\title{
Calcium influx and sperm-evoked calcium responses during oocyte maturation and egg activation
}

\author{
Ya-Ru Xu ${ }^{1}$ and Wan-Xi Yang ${ }^{1}$ \\ ${ }^{1}$ The Sperm Laboratory, College of Life Sciences, Zhejiang University, Hangzhou, China \\ Correspondence to: Wan-Xi Yang, email: wxyang@spermlab.org \\ Keywords: oocyte maturation, calcium influx, egg activation, calcium oscillation, calcium response \\ Received: May 09, $2017 \quad$ Accepted: June 19, $2017 \quad$ Published: July 29, 2017
}

Copyright: $\mathrm{Xu}$ et al. This is an open-access article distributed under the terms of the Creative Commons Attribution License 3.0 (CC BY 3.0), which permits unrestricted use, distribution, and reproduction in any medium, provided the original author and source are credited.

\section{ABSTRACT}

Under the guidance and regulation of hormone signaling, large majority of mammalian oocytes go through twice cell cycle arrest-resumption prior to the fertilized egg splits: oocyte maturation and egg activation. Cytosolic free calcium elevations and endoplasmic reticulum calcium store alternations are actively involved in triggering the complex machineries and events during oogenesis. Among these, calcium influx had been implicated in the replenishment of endoplasmic reticulum store during oocyte maturation and calcium oscillation during egg activation. This process also drove successful fertilization and early embryo development. Storeoperated $\mathrm{Ca}^{2+}$ entry, acts as the principal force of calcium influx, is composed of STIM1 and Orai 1 on the plasma membrane. Besides, transient receptor potential channels also participate in the process of calcium inwards. In this review, we summarize the recent researches on the spatial-temporal distribution of store-operated calcium entry components and transient receptor potential channels. Questions about how these channels play function for calcium influx and what impacts these channels have on oocytes are discussed. At the time of sperm-egg fusion, sperm-specific factor(s) diffuse and enable eggs to mount intracellular calcium oscillations. In this review, we also focus on the basic knowledge and the modes of action of the potential sperm factor phospholipase $C$ zeta, as well as the downstream receptor, type 1 inositol 1,4,5-trisphosphate receptor. From the achievement in the previous several decades, it is easy to find that there are too many doubtful points in the field that need researchers take into consideration and take action in the future.

\section{INTRODUCTION}

Oocytes in most mammal species undergo twice cell cycle arrests during cell meiosis. The first arrest happens at diplotene stage of meiosis I, termed germinal vesicle oocyte (GV oocyte). The second arrest appears at metaphase of meiosis II oocyte (MII oocyte). Under the stimulus of luteinizing hormone (LH), GV oocytes turn on the so-called "oocyte maturation" process, firstly detach from the arrest state, later undergo GV breakdown (GVBD) and endoplasmic reticulum (ER) reorganization. The oocytes accomplish the preparation for fertilization, finally terminate in MII stage. Subsequently, the ovulatory MII oocytes resume meiosis in response to sperm entry. The following events constitute the "egg activation" process: cortical granule exocytosis, polyspermy blockage via cortical reaction, meiosis II proceeding, genetic material replicating, second polar body (2PB) and pronuclei formation. Close attention had been paid to the molecular signaling basis of arrest exit downstream calcium $\left(\mathrm{Ca}^{2+}\right)$ oscillation. The cytostatic factor, maturation-promoting factor (MPF), is composed of catalytic subunit cyclin-dependent kinase 1 (Cdk1)/cell division cycle protein 2 (cdc2) and regulatory subunit cyclin $\mathrm{B}$. The inactivated MPF enforces $\mathrm{Ca}^{2+}$ command to call for cell cycle resumption. Two multiple interacting programs are responsible for the inactivation of MPF. On the one hand, the phosphorylation state of Cdk1/ $\mathrm{Cdc} 2$ is coordinated by kinases and phosphatases. On the other hand, the synthesis and degradation of cyclin $\mathrm{B}$ are balanced. Reactivation and down-regulation of Wee1B exercised a great influence on $\mathrm{Cdk} 1 / \mathrm{Cdc} 2$ kinase 
activity and pronucleus forming, and Wee1B inhibited Cdk1/Cdc2 activity by phosphorylating tyrosine 15 [1]. Wee1B activity could be activated by the phosphorylation effect of upstream type II $\mathrm{Ca}^{2+} /$ calmodulin-dependent protein kinase (CaMKII) at Serine 15 [1]. At the other end of the scale are the downregulated phosphatases, like Cdc25A and Cdc25B, which could dephosphorylate $\mathrm{Cdk} 1 / \mathrm{Cdc} 2$ and stabilize meiotic arrest [2,3]. Activation of anaphase promoting complex/cyclosome (APC/C) and its co-factor $\mathrm{Cdc} 20\left(\mathrm{APC}^{\mathrm{cdc} 20}\right)$ could promote the proteolytic degradation of cyclin $\mathrm{B}$ and then inactivate MPF, finally release oocyte from MII arrest $[4,5]$. What's more, Wee1B could also mediate the degradation of cyclin $\mathrm{B}$ by activating APC/C [3]. The early mitotic inhibitor 1 (Emi1) could inhibit the activity of APC/C-APC ${ }^{\text {cdc2 } 20}[6]$. In addition to MPF, cyclic adenosine 3',5'-monophosphate (cAMP) was also reported to maintain oocyte arrest [7, 8]. There are two sources of cAMP: the adjacent somatic follicular cells and the oocyte itself. In somatic follicular cells, cAMP could be catalyzed by adenylyl cyclase (AC) of ATP and transported into oocyte through gap junction [9]. In oocyte, G-protein-coupled receptors (GPCR) in the plasma membrane (PM) could activate $\mathrm{AC} 3$ to produce cAMP [10]. As the downstream of cAMP, protein kinase A (PKA) could balance the activities of the Wee1B kinase and $\mathrm{Cdc} 25$ phosphatase [11]. LH surge acts as a gap junction blocker to guarantee low concentration of cAMP in oocyte to assist cell resumption $[12,13]$. The intricate and detailed signal interactions could be referred to many review papers $[4,14]$. The signal pathways underlying oocyte arrest and resumption were depicted in Figure 1.

The inaugurator of MII oocyte resumption has been defined as a series of rapid, transient increase of intracellular calcium $\left(\left[\mathrm{Ca}^{2+}\right]_{i}\right)$, known as " $\mathrm{Ca}^{2+}$ oscillation", triggered by specific sperm factor. The successful cell cycle arrest and punctual exit are orchestrated by well-balanced $\left[\mathrm{Ca}^{2+}\right]_{\mathrm{i}}$ concentrations and complicated regulators/pathways, deeper issues needs to be solved in the future. The $\mathrm{Ca}^{2+}$ oscillation in mammalian eggs is featured by a train of long-lasting repetitive intracellular $\mathrm{Ca}^{2+}$ transients [15]. The frequency and duration of $\mathrm{Ca}^{2+}$ oscillations are different in various species. Take mouse eggs for example, the large transient increase lasts about 2 minutes, followed by repetitive transients lasting 0.5 minutes and occurring at 3 minutes intervals [16]. The $\mathrm{Ca}^{2+}$ oscillation in mouse eggs lasted until the pronuclear formation $[17,18]$. Actually, the inordinate oscillatory pacemaker and $\mathrm{Ca}^{2+}$ oscillation during egg maturation and activation usually leads to eggto-embryo transition disorders $[16,19]$.

The fine-adjusted $\left[\mathrm{Ca}^{2+}\right]_{\mathrm{i}}$ concentration is tightly and complicatedly regulated by various factors. It could be divided into the all-around administration of the $\mathrm{Ca}^{2+}$ entrance and exit. External $\mathrm{Ca}^{2+}\left(\left[\mathrm{Ca}^{2+}\right]_{\mathrm{e}}\right)$ support $\mathrm{Ca}^{2+}$ influx and the authenticated channels that mediate $\mathrm{Ca}^{2+}$ influx during maturation and fertilization could be the type of plasma membrane channel(s), like storeoperated $\mathrm{Ca}^{2+}$ entry (SOCE) and Cav3.2 [20, 21, 22]. Plasma membrane $\mathrm{Ca}^{2+}$-ATPase (PMCA) is a kind of $\mathrm{Ca}^{2+}$ pump-out channel that had been focused on. In presence of high concentrations of $\mathrm{Gd}^{3+}$, the initial $\left[\mathrm{Ca}^{2+}\right]$ $i$ was broadened and the interval between spikes was widened, indicating the active participation of PMCA in $\left[\mathrm{Ca}^{2+}\right]_{\mathrm{i}}$ oscillations shaping [21]. ER plays a role as " $\mathrm{Ca}^{2+}$ reservoir" and is indispensable for $\mathrm{Ca}^{2+}$ oscillations. Replenishment and discharge of $\left[\mathrm{Ca}^{2+}\right]_{\mathrm{ER}}$ require sarcoendoplasmic reticulum $\mathrm{Ca}^{2+}$ ATPases (SERCA) and type 1 inositol 1,4,5-trisphosphate receptor (IP3R1) function during $\left[\mathrm{Ca}^{2+}\right]_{\mathrm{i}}$ oscillations. Addition of SERCA inhibitors (thapsigargin or cyclopiazonic acid (CPA)) could perturb $\mathrm{Ca}^{2+}$ oscillations by reducing basal $\left[\mathrm{Ca}^{2+}\right]_{\mathrm{ER}}$ levels and holding the recovery back $[21,23,24]$.

As mentioned before, the fertilized $\mathrm{Ca}^{2+}$ fluctuation is stirred up by a specific sperm factor. The identity of such sperm factor was debatable and blurry over the past few decades, and many theories upgraded along with constantly deepened researches. Among these, phospholipase C zeta (PLC $)$ ), was found to depend on the substrate phosphatidylinositol 4,5-biphosphate (PI(4,5)P2) to produce inositol 1,4,5-trisphosphate (IP3), and activate IP3R1 to release $\mathrm{Ca}^{2+}$ from ER store $[25,26,27,28]$. Meanwhile, another controversial protein, postacrosomal sheath WW domain-binding protein (PAWP), made its first appearance in 2007 and disputes about its real function have cropped up repeatedly in recent years [29]. In this review, we summarized the findings in the past decades on the characteristics and the related signaling pathways underlying $\mathrm{Ca}^{2+}$ inward mobilization, such as ER-STIM1Orail pathway $[19,30,31]$, actin filament-TRPV3 pathway $[32,33]$, and TRPM7-SOCE pathway $[34,35$, $36]$. We also discussed the influence to oocyte maturation and activation. In addition, we described and discussed the sperm factors which operate $\mathrm{Ca}^{2+}$ release from ER during mammalian oocytes development and embryogenesis. The antagonists, inhibitors and labels used in the course of the study of $\mathrm{Ca}^{2+}$ are summed up in Table 1 .

\section{$\mathrm{Ca}^{2+}$ INFLUX SUPPORTS ER STORES REFILLING, $\mathrm{Ca}^{2+}$ OSCILLATIONS AND DOWNSTREAM EVENTS OF EGG ACTIVATION}

The existence of $\mathrm{Ca}^{2+}$ influx is vital for various physiological processes. When loading with IP3, neither mouse GV oocyte nor MII oocyte produced any $\mathrm{Ca}^{2+}$ release in $\mathrm{Ca}^{2+}$-free medium, but the $\mathrm{Ca}^{2+}$ oscillations are observed after $\mathrm{Ca}^{2+}$ addition [19]. The time cause of cation influx during fertilization-induced $\mathrm{Ca}^{2+}$ oscillations was evaluated by $\mathrm{Mn}^{2+}$ quenching method, and found that the internal flow augmented approximately 3 -fold after each $\mathrm{Ca}^{2+}$ transient and gradually calmed down to the 
basal level until the next transient occurs in mouse eggs [37]. The functions of $\mathrm{Ca}^{2+}$ influx are versatile. It not only maintains $\mathrm{Ca}^{2+}$ oscillations by replenishing $\mathrm{Ca}^{2+}$ stores during oocyte maturation, but also provides an important spatially restricted $\mathrm{Ca}^{2+}$ signal required for complete egg activation at fertilization. For example, in intracytoplasmic sperm injection (ICSI) and/or in vitro fertilization (IVF) fertilized mouse eggs, $\mathrm{Ca}^{2+}$ influx across PM, instead of the intracellular $\mathrm{Ca}^{2+}$ buffering, is required for downstream events of egg activation [20, 37, 38]. They suspected that the $\mathrm{Ca}^{2+}$ influx through SOCE was a precondition for the successful IP3-mediated $\mathrm{Ca}^{2+}$ leak. The CaMKII $\gamma$ activation pathway was found as a downstream function cascade of $\mathrm{Ca}^{2+}$ influx in fertilized mouse oocyte as CACaMKII $\gamma$ cRNA-injected eggs formed a second polar body and pronucleus [20].

\section{Protein composition and molecular interactions of SOCE}

SOCE is composed of two kinds of proteins: stromal interaction molecule 1 (STIM1) and Orail. STIM1, discovered in 1870, was characterized by malignancies/ tumor-related function from human chromosome region 11 15.5 [39]. STIM proteins (STIM1 and STIM2), the single transmembrane-spanning proteins resident in the ER membrane, exist as dimers, and STIM1 migrates to the ER-PM junctions as "puncta" to tether Orai $\mathrm{Ca}^{2+}$ channels [40, 41]. The $\mathrm{Ca}^{2+}$ sensor role of STIM proteins in response to store depletion is dependent on its luminal single EF-hand $\mathrm{Ca}^{2+}$ binding domain [42]. The association of N-terminal domain leads to the unfolding and extension of the C-terminal domain, which is known as the STIMOrai activating region (SOAR)/channel-activating domain (CAD)/Orail-activating small fragment (OASF) $[31,43,44,45]$. There are three Orai isoforms encoded in mammalian genomes. Orai3 resided and functioned in both the GV and MII oocyte membrane [19]. From the results of overexpression of Orai1, STIM1 or Orai3 in GV oocytes and MII oocyte, we could learn that, STIM1 associated with either Orai1 or Orai3 to mediate $\mathrm{Ca}^{2+}$ influx in the GV oocyte, but clustered with Orai1 only in the MII oocyte [19]. Orai1, a plasma membrane protein with four transmembrane domains, interacts with STIM1 by its cytoplasmic N- and C- termini to form

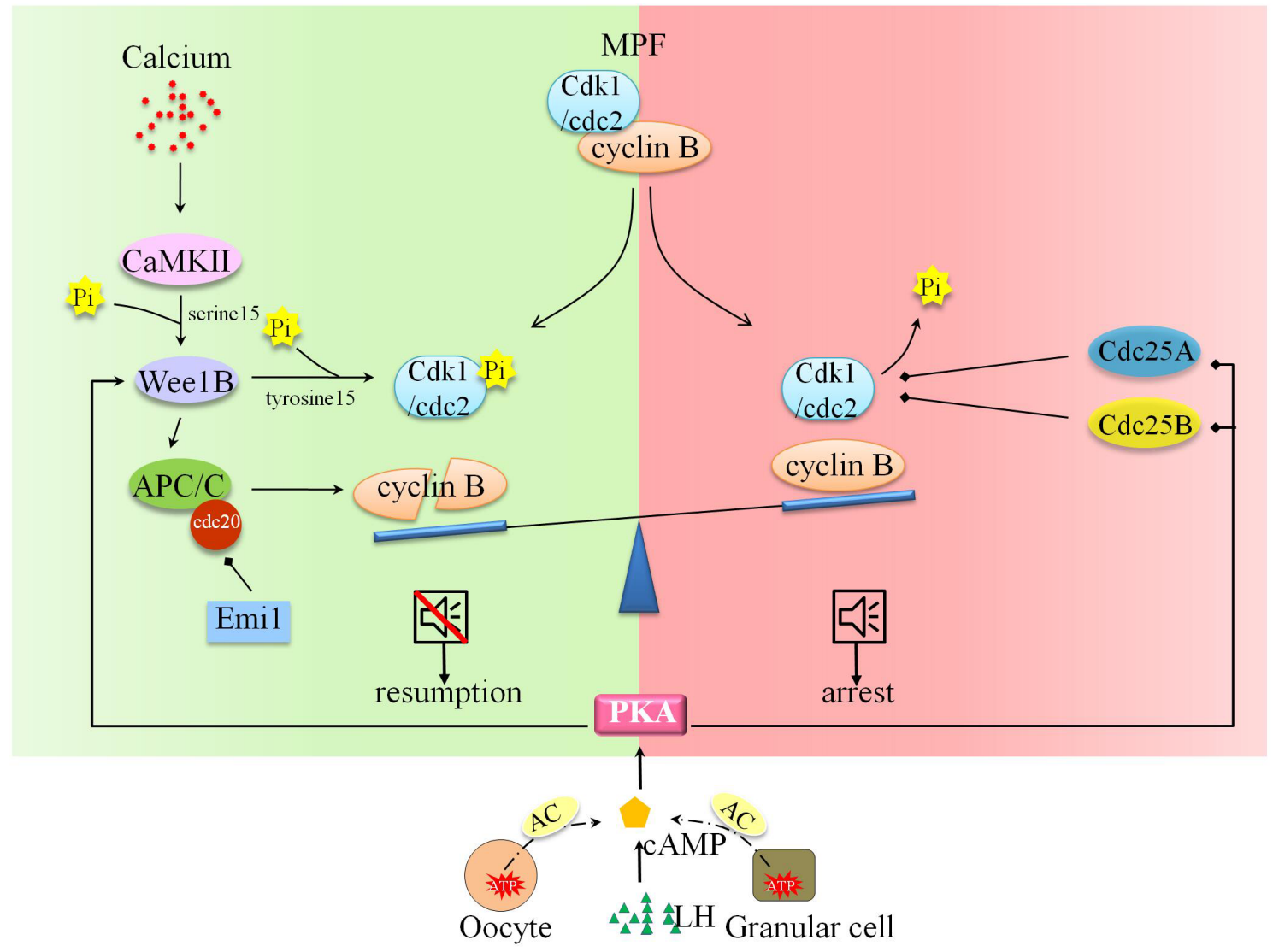

Figure 1: Molecular and signal mechanism underpinning oocyte arrest and cell resumption. Oocyte arrest and resumption are balanced by two determinants: MPF and cAMP. The inactivation of MPF and regimentation of cAMP in arrested oocyte assist cell resumption. The phosphorylation status of $\mathrm{Cdk} 1 / \mathrm{cdc} 2$ is activated by $\mathrm{Ca}^{2+}-\mathrm{CaMKII}-$ Wee1B pathway and inactivated by PKA-Cdc25A pathway. The degradation of cyclin B is promoted by $\mathrm{Ca}^{2+}$-CaMKII-Wee1B- APC/C pathway. What's more, LH surge facilitates oocyte resumption via AC-cAMP-PKA pathway. 
Table 1: Diverse pharmacological agents and/or materials used in the study of $\mathrm{Ca}^{2+}$ function in oocytes and eggs.

\begin{tabular}{|c|c|c|c|c|}
\hline Name & application & Mechanism of action & demerits & references \\
\hline 2-APB & $\begin{array}{|lll|}\begin{array}{l}\text { suppress } \\
\text { release }\end{array} & \text { intracellular } \mathrm{Ca}^{2+} \\
\end{array}$ & inhibit IP3 receptor; inhibit SOCE & $\begin{array}{l}\text { inequality in different cell } \\
\text { types }\end{array}$ & {$[38,115]$} \\
\hline 2-APB & TRPM7; activate TRPV3 & unknown & - & {$[34,35]$} \\
\hline NS8593 & inhibit TRPM7 channel & $\begin{array}{l}\text { interaction between the pore-forming } \\
\text { loop of TRPM7 and the imidazole ring of } \\
\text { NS8593 }\end{array}$ & $\mathrm{Mg}^{2+}$ dependence & {$[57,116]$} \\
\hline Naltriben & activate TRPM7 channel & most likely act via the TRP domain & - & {$[57,117]$} \\
\hline $\mathrm{Sr}^{2+}$ & $\begin{array}{l}\text { replace external } \mathrm{Ca}^{2+} \text {; induce } \\
\text { parthenogenesis }\end{array}$ & $\begin{array}{l}\text { potentiate the InsP3 receptors (InsP3R) } \\
\text { without generating IP3; through the major } \\
\text { route of TRVP3 }\end{array}$ & & {$[32,65,118]$} \\
\hline BAPTA & calcium chelator & & - & \\
\hline fluo-3/8H & fluorescent calcium indicator & & $\begin{array}{l}\text { cause damage to oocytes and } \\
\text { interfere with later embryo } \\
\text { development }\end{array}$ & {$[37]$} \\
\hline ionomycin & $\begin{array}{l}\mathrm{Ca}^{2+} \text { ionophore to release } \\
\text { intracellular stores } \mathrm{Ca}^{2+}\end{array}$ & $\begin{array}{l}\text { alter the plasma membrane permeability } \\
\text { or act directly on intracellular organelles } \\
\text { which release } \mathrm{Ca}^{2+}\end{array}$ & $\begin{array}{l}\text { potentially cytotoxic or } \\
\text { mutagenic }\end{array}$ & [119] \\
\hline carvacrol & a TRPV3 agonist & & & {$[120]$} \\
\hline heparin & $\begin{array}{l}\text { competitive inhibitor of the } \\
\text { inositol } 1,4,5 \text { trisphosphate } \\
\text { receptor (InsP3R) }\end{array}$ & & - & {$[20,26]$} \\
\hline $\begin{array}{l}\text { Inp54p } \\
\text { phosphatase }\end{array}$ & $\begin{array}{l}\text { specifically dephosphorylate } \\
\text { PI }(4,5) \text { P2 }\end{array}$ & & - & {$[91]$} \\
\hline thapsigargin, & detect $\mathrm{Ca}^{2+}$ in ER stores & inhibit the $\mathrm{ER} \mathrm{Ca}^{2+}$ ATPase (SERCA) & $\begin{array}{l}\text { As the endogenous leak } \\
\text { pathway is slow, thus as } \\
\text { stores are being emptied, } \\
\mathrm{Ca}^{2+} \text { is buffered and extruded } \\
\text { out of the cell }\end{array}$ & {$[38,56]$} \\
\hline A23187 & $\begin{array}{l}\mathrm{Ca}^{2+} \text { ionophore to activate egg } \\
\text { artificially }\end{array}$ & & $\begin{array}{l}\text { only elicit a single rise in } \\
\mathrm{Ca}^{2+}\end{array}$ & {$[121]$} \\
\hline thimerosal & induce $\left[\mathrm{Ca}^{2+}\right]_{\mathrm{i}}$ oscillations & sensitize IP3Rs without generating IP3 & - & {$[122]$} \\
\hline $\begin{array}{l}\text { Cameleon } \\
\text { D1ER }\end{array}$ & $\mathrm{Ca}^{2+}$ indicator & $\begin{array}{l}\text { fluorescence resonance energy transfer } \\
\text { (FRET)-based }\end{array}$ & - & {$[20,37,123]$} \\
\hline Rhod-2 & $\begin{array}{l}\text { measure mitochondrial } \\
\mathrm{Ca}^{2+} / \text { report cytoplasmic }\left[\mathrm{Ca}^{2+}\right]_{\mathrm{i}}\end{array}$ & & - & {$[21,69]$} \\
\hline $\mathrm{Gd} 3+$ & reduce $\mathrm{Ca}^{2+}$ influx and efflux & inhibit PMCA & - & {$[21,124]$} \\
\hline $\mathrm{CPA}$ & prevent $\left[\mathrm{Ca}^{2+}\right]_{\mathrm{ER}}$ increase & inhibit SERCA & - & {$[21]$} \\
\hline $\begin{array}{l}\text { mibefradil or/ } \\
\text { pimozide }\end{array}$ & inhibit $\mathrm{CaV} 3.2$ & $?$ & - & {$[22,125]$} \\
\hline TPEN & simulate store depletion & chelate store $\mathrm{Ca}^{2+}$ & & [19] \\
\hline
\end{tabular}

the SOCE channel. The $\mathrm{Ca}^{2+}$ selective pore is composed of three layer construction by six Orail subunits: $\mathrm{Ca}^{2+}$ selectivity filter layer towards the extracellular end of the pore formed by glutamate residues that bind $\mathrm{Ca}^{2+}$ ions, the transmembrane helices (TM2-4) layer and the inner most transmembrane 1 (TM1) helices layer [40, 46, 47]. Recently, the gating mechanism of Orail by STIM1 was investigated, it occurred through a modest rotation of the pore helix, destroyed the V102-F99 hydrophobic band by shifting F99 residues away from the central pore axis, thereby increasing pore hydration and permitting ion conduction [41]. A more bewilderment, the signaling crosstalk underlies STIM1 recruitment of Orai1 and STIM1-Orai1 interaction remains enigmatic. In HEK293 cells, the phosphorylation of STIM1 at ERK1/2 target sites (i.e. in serine residues 575,608 and 621) is necessary for the activation of SOCE [48]. In human pulmonary aortic endothelial (HPAE) cells, the phosphorylation at tyrosine residue 361 within the SOAR domain is a pivotal switch to link STIM1 puncta to gating of Orail channels [49].
From the perspective that two tyrosine residues lie within the SOAR domain of STIM1, the role of these potential phosphorylation sites in regulating oocytes and eggs SOCE remains to be disclosed.

\section{SOCE in oocyte maturation}

In mammalian oocyte, whether SOCE exerts effects during maturation had been explored [30, 50, 51]. However, there is still a controversial dispute about the real occurrence of SOCE in maturing oocytes. Using the same thapsigargin and $\mathrm{Ca}^{2+}$ add-back method, GómezFernández group reported that SOCE-mediated $\mathrm{Ca}^{2+}$ entry was silent in GV, GVBD and MI stage, increased sharply in MII oocyte [50]. Nevertheless, diametrically opposed to the above findings, Cheon group and Lee group insisted that $\mathrm{Ca}^{2+}$ influx decreased along with $\left[\mathrm{Ca}^{2+}\right]_{\mathrm{ER}}$ content increased, which showed the gradual inactivation of $\mathrm{Ca}^{2+}$ entry in mouse $[19,38]$. In consideration of the inaccuracy of thapsigargin, Lee group verified their results through 
adopting a more direct approach to measure $\mathrm{Ca}^{2+}$ store by using the $\mathrm{Ca}^{2+}$ ionophore, ionomycin [19] (Table 1). The expression profile and subcellular localization of STIM1 and Orail disclosed the underlying molecular basis. For the former, quantitative real-time PCR and Western blot results revealed a low level of STIM1 at GV in the cortical fraction of the ER, followed by a sharp increase at the GVBD with homogeneously distribution throughout the periphery of the cell, but a steady expression of Orai1 with a scattered distribution in the plasma membrane, suggesting the decisive effect of STIM1 to the occurrence of SOCE [50, 52]. The low STIM1-Orail co-localization under store depletion conditions in immature oocytes suggested the close positive correlation between STIM1Orail co-localization and SOCE activation during meiotic progression [50]. For the latter, the waning could be attributed to the progressively disabled SOCE, as the $\mathrm{Ca}^{2+}$ influx could be clearly enhanced in all stages of maturation by over-expressing of human-Stim1YFP, especially in GV oocytes [38]. Interestingly, the cellular distribution of Stim1 and Orail changed during maturation, which coincided with the decline: STIM1 was patched throughout the GV oocyte, more diffuse in GVBD oocyte, more disperse as maturation progressed; Orai1 was highly enriched at the PM, weaker and internalized from PM to an intracellular early endosomal compartment [19, 38]. After ER store depletion, Orail translocated back to the cell membrane and coupled to an increase in
STIM1 clusters [19]. What's more, the ability of Stim1 to undergo "puncta" formation and migration to the cortex changed along with the decline in $\mathrm{Ca}^{2+}$ influx. The colocalization of hStim 1 and hOrail diminished during this process [38]. Researchers in each group failed to provide a reasonable explanation for such discrepancy. There is speculation that the posttranslational (such as phosphorylation) and conformational modifications of STIM1 may exercise a great influence on SOCE activities. In HEK293 cells and human pulmonary aortic endothelial (HPAE) cells, the phosphorylation of STIM1 at several sites (i.e. in serine residues 575, 608, 621 and tyrosine residue 361 ) is necessary for the activation of SOCE [48, 49]. The auto-inhibitory domain was needed to expose by STIM1 to achieve full activation of SOCE [53]. What's more, this brings into question the different physiological significance generated by the unusual distribution of SOCE components and this remains to be investigated.

Proper content of SOCE components has significant physiological effect to the follow-up activities and development. The expression pattern is shown up as higher in immature (GV-stage) oocytes and weak in MII mature oocytes [54]. Orai1 downregulation by injecting siRNA in porcine oocyte prior to maturation showed the abolished $\mathrm{Ca}^{2+}$, suggesting the key role of Orail in store-operated $\mathrm{Ca}^{2+}$ entry [54]. In contrast, down-regulation of STIM1 or Orail by siRNA injection into porcine $\mathrm{GV}$ oocyte did not reduce the $\mathrm{Ca}^{2+}$ store content and $\mathrm{Ca}^{2+}$ oscillations in

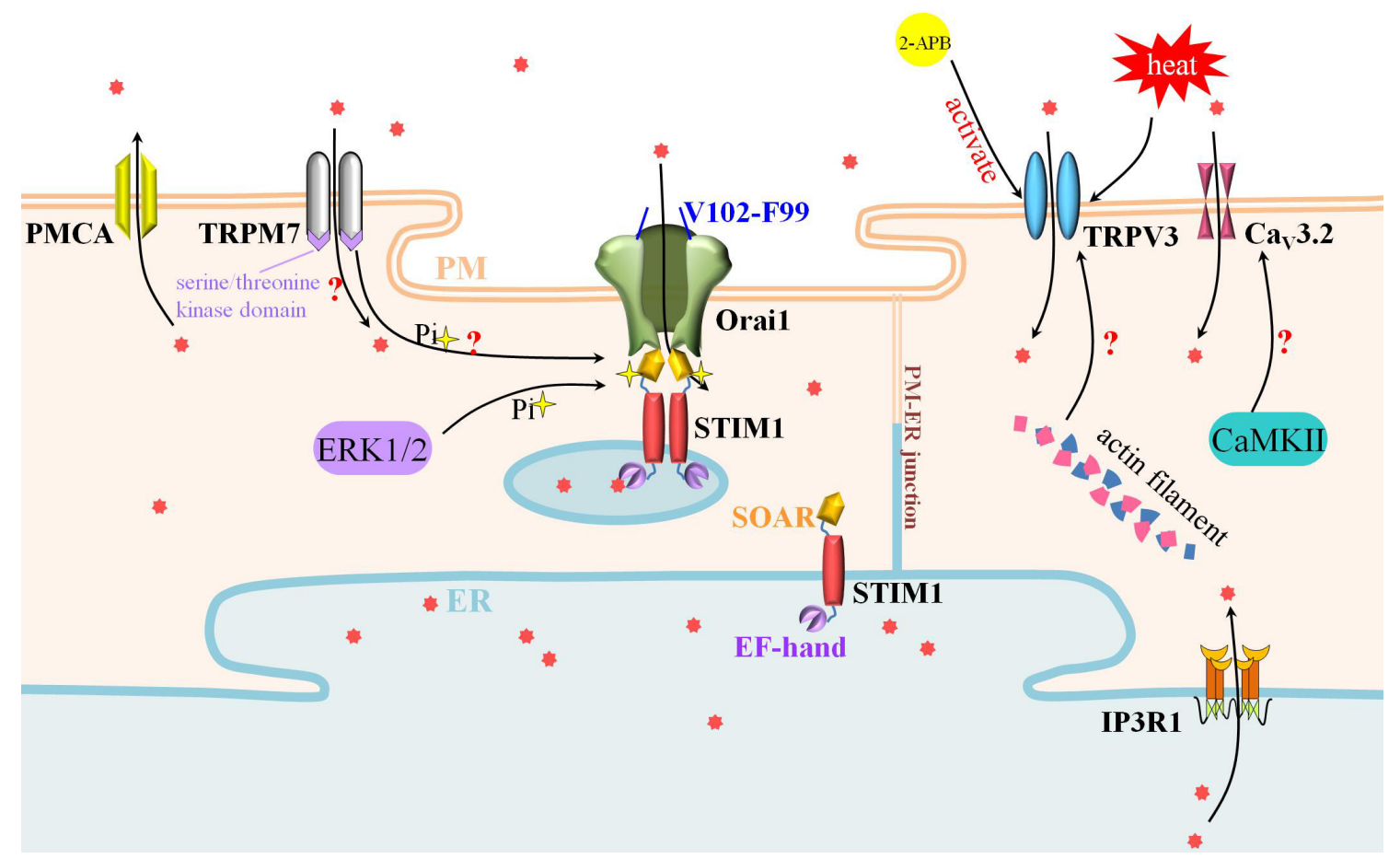

Figure 2: SOCE, TRPV3 and TRPM7 participate actively in $\mathrm{Ca}^{2+}$ influx during oocyte maturation and egg activation. SOCE is composed of STIM1 and Orail. STIM1 in the ER membrane tethered Orail in the PM to deliver the entrance of $\mathrm{Ca}^{2+}$ signal. Meanwhile, $\mathrm{Ca}^{2+}$ influx mediated by TRPV3 is crucial to oocyte maturation and activation. The polymerization of actin filament may promote the expression and PM-distribution of TRPV3. Besides the cation channel, TRPM7 could also phosphorylate SOCE by its serine/ threonine kinase domain. 
another research [55]. The difference may be explained by the existence of endogenous STIM1 and Orai1. However, overexpression of STIM1 and Orai1 in porcine oocyte disrupted the maintenance of the long-lasting $\mathrm{Ca}^{2+}$ signal and led to the fertilization failure $[54,55]$.

\section{SOCE in egg activation}

The location of STIM1 changed during early fertilization in mouse oocytes. In resting MII oocytes, STIM1 co-localized with the ER marker calreticulin in the small and discrete areas or clusters, translocated to larger areas like PM concomitant with the intracellular $\mathrm{Ca}^{2+}$ stores emptying induced by TG/ionomycin/IVF [52]. The role for STIM1 and SOCE in the calcium signaling during early stages of mouse oocyte fertilization had been proven in these findings. Both protein expression (STIM1CT and Orail-NT) and SOCE inhibitors (SKF-96365 and 2-APB) failed to regulate the $\mathrm{Ca}^{2+}$ oscillations, which showed the rare contribution of SOCE in $\mathrm{Ca}^{2+}$ oscillation maintaining in fertilized mouse eggs [37]. In contrast, the expression of STIM1-CCb9 could enhance the rate of
$\mathrm{Mn}^{2+}$ entry and augment the oscillation frequency, a better explanation was that STIM1 may assist the $\mathrm{Ca}^{2+}$ pumpmediated $\mathrm{Ca}^{2+}$ uptake and the IP3R/Ca ${ }^{2+}$ channels-mediated pump-out [37]. Given that, SOCE can be chosen as a key maturity assessment indicator for mouse oocyte. However, $\mathrm{Gd}^{3+}$ and Synta66 (two SOCE inhibitors) could not prevent ICSI-induced $\mathrm{Ca}^{2+}$ entry, which indicated that the requisite $\mathrm{Ca}^{2+}$ entry may be supported by alternative $\mathrm{Ca}^{2+}$ influx channels [20].

In porcine eggs, SOCE was confirmed to be the only prerequisite to reload the intracellular stores and sustain the repetitive $\mathrm{Ca}^{2+}$ signal at fertilization. Different SOCE inhibitors (gadolinium, 3,5-bis (trifluoromethyl) pyrazole 2, tetrapandin-2) were employed into the porcine eggs, and the $\mathrm{Ca}^{2+}$ entry that was triggered by thapsigargin-induced store depletion was blocked, the fertilization $\mathrm{Ca}^{2+}$ signal ceased abruptly [55]. Injection of STIM1 siRNA to porcine oocyte prior to fertilization destroyed the characteristics of fertilization, as failing to generate repetitive $\mathrm{Ca}^{2+}$ signals and refill stores, perturbing embryo development [56]. And overexpressed h-STIM1 and h-Orail up-regulated the basal $\mathrm{Ca}^{2+}$ levels in mouse oocyte, nevertheless, overexpression of STIM1 had no effect to porcine oocyte

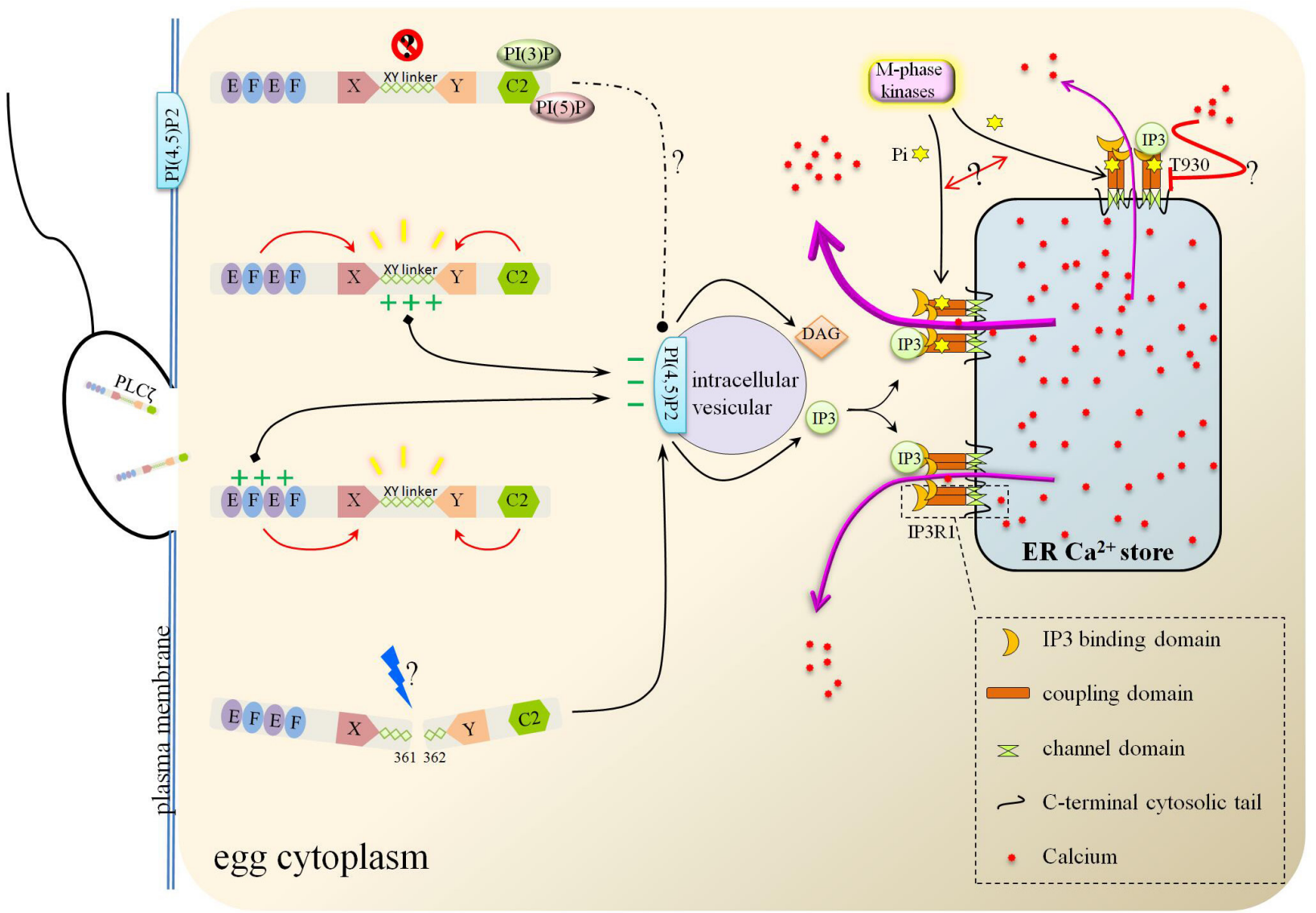

Figure 3: The action modes of PLC $\zeta$ and $\mathrm{Ca}^{2+}$ release from ER stores. Either XY linker or EF hand domain of PLC $\zeta$ binds with the intracellular vesicular PI(4,5)P2 due to their positive charges. PI(4,5)P2 was then hydrolyzed to IP3 and DAG. As the ER membrane channel, IP3R1 mediated the $\mathrm{Ca}^{2+}$ flowing out from ER after binding with IP3. During this import process, M-phase kinases phosphorylated IP3R1 and promoted $\mathrm{Ca}^{2+}$ efflux. 
which hinted the self-sufficiency of endogenous STIM1 function $[19,56]$.

Recently, the rule of SOCE in oocyte $\mathrm{Ca}^{2+}$ signaling was overthrown and the indispensable status of SOCE in $\mathrm{Ca}^{2+}$ entry and fertilization became controversial. Oocytespecific conditional knockout (cKO) mice for STIM1 and STIM2 respectively, STIM1/2 double cKO mice, and Orai1-null mice were generated [57]. These three proteinsmissing models showed no difference in $\mathrm{ER} \mathrm{Ca}^{2+}$ stores or $\mathrm{Ca}^{2+}$ influx at GV stage, no difference in the pattern of $\mathrm{Ca}^{2+}$ oscillations after fertilization, and no difference in the normal fertility. All the above results proved the negligible effect of SOCE during oocyte fertilization [57]. This makes the definitive conclusions remain elusive and everything would get murkier and murkier. Whenever we have a new data point, with an unknown output value, we put it through the model and produce our expected output through constant exploration.

\section{THE CONTRIBUTION OF TRP CHANNELS TO $\mathrm{Ca}^{2+}$ PERMEATION}

The Transient Receptor Potential (TRP) channels family proteins are composed of about 30 members. They can be divided into in six subfamilies: TRPC-"canonical", TRPM-"melastatin", TRPV-"vanilloid", TRPA-"ankyrin", TRPML-"mucolipin" and TRPP/PKD-"polycystin" [58, 59]. As cations conductors, TRP channels have weak sensitivity to voltage, and initiate a plethora of cellular changes in response to various stimuli such as osmolarity, $\mathrm{pH}$, temperature, taste, pheromones and intracellular stimuli such as $\mathrm{Ca}^{2+}$ and phosphatidylinositol signal transduction pathways, and plant compounds [59]. Among them, TRPV3 and TRPM7 hold great significance for $\mathrm{Ca}^{2+}$ signaling in mammal oocytes and eggs.

\section{TRPV3}

As a heat-sensitive protein, TRPV3 was firstly cloned and characterized in Keratinocytes [60]. It is composed by two coiled-coil domains in $\mathrm{NH}_{2}$ terminal, intermediate four predicted ankyrin domains and six putative transmembrane domains in C-terminal [60]. The functional expression of mouse PM-located TRPV3 had been investigated. It increased in accordance with the grade of maturity during oocyte maturation, showing concretely as measurable currents at GV, small at MI, and maximum at MII stage [32]. By means of voltage clamp and calcium imaging measurements of wild type and TRPV3-knock out mouse oocytes, TRPV3 was defined to mediate $\mathrm{Ca}^{2+}$ permeation and initiate egg activation [32]. Nevertheless, TRPV3-induced $\mathrm{Ca}^{2+}$ permeation meant nothing to fertilization-associated $\left[\mathrm{Ca}^{2+}\right]_{\mathrm{i}}$ oscillations in mouse [32]. Recently, 2-APB was confirmed to target TRPV3 selectively to increase $\left[\mathrm{Ca}^{2+}\right]_{\mathrm{i}}$ without affecting
IP3R1 [33]. In the same study, the expression and/or function of TRPV3 were found to be regulated by actin microfilaments in mouse egg [33]. It could be attributed to the blockage of the recycling of TRPV3 channels to $\mathrm{PM}$ by the depolymerization of actin. In consideration of temperature sensibility, TRPV3 may protect the balance of $\mathrm{Ca}^{2+}$ regulation against extreme, hostile temperature milieu. There is still a need to figure out unknown endogenous direct activators and targets of TRPV3 in oocyte and egg in the future.

\section{TRPM7}

Strontium is able to initiate oscillations in experimental operation. However, strontium was able to mount oscillations in TRPV3-lacking GV oocyte, indicating the fruitless contribution of TRPV3 and the possible commitment of TRPM7- and/or TRPM6-like channels to mouse GV oocyte [35]. Based on publicly available microarray data and electrophysiological evidence, TRPM7-like channels were picked up. TRPM7 has a large TRPM homology region (around 700 amino acids) in the N-terminal, followed by a TRP domain C-terminal to the transmembrane segments, and coiledcoil domain and serine/threonine kinase domain in the C-terminal [34]. TRPM7 homomers were identified to be functionally expressed in both GV oocytes and eggs, last until post-fertilization [35]. TRPM7 is involved in the ubiquitous $\mathrm{Ca}^{2+}$ influx pathway that regulates many physiological functions including oocyte maturation and fertilization. It was demonstrated to contribute significantly to spontaneous $\mathrm{Ca}^{2+}$ influx in GV oocytes and $\mathrm{Ca}^{2+}$ influx following fertilization in mouse eggs through pharmacological assessment of TRPM7 inhibitors $\left(\mathrm{Mg}^{2+}\right.$ and NS8593) and activator (Naltriben) $[35,57]$. TRPM7 knocking-out model satisfied the research requirement and more potential functions are discovered. TRPM7 was essential for normal embryonic development as trpm7 knock-out mice are embryonic lethal before E7.5 $[61,62]$. The blockade of TRPM7 (trpm7 knocking-out) impaired normal pre-implantation development, delayed progression to the morula stage, and inhibited blastocyst formation [35]. The first priorities are to assess the essence, mechanism and magnitude behind these effects.

It's worth noting that the connection between TRPM7 and SOCE should be considered when discussing TRPM7 effects. A recent research depicted an acute functional link between TRPM7 and SOCE for the first time. Researchers found that in chicken DT40 B lymphocytes, suppression of TRPM7 by pharmacological and molecular ways lessened SOCE while overexpression of TRPM7 rescued SOCE. TRPM7 possesses dual identity as both an ion channel which can depolarize cells and increase intracellular calcium and a kinase which can phosphorylate downstream proteins [34, 63, 64]. Interestingly, using kinase-deficient mutants, TRPM7 was 
proved to regulate SOCE through its kinase domain, might affect STIM indirectly by engaging another protein partner of STIM or Orai proteins [36]. This gave us a new facet of SOCE-TRPM7 interaction; the previous TRPM7-Ca ${ }^{2+}$ conditioning findings might result from the additional secondary, indirect support of SOCE via the kinase activity of TRPM7.

Along with the natural aging, physiological reaction of $\mathrm{Ca}^{2+}$ oscillations remains unchanged despite deterioration in the oocyte's ability to replenish $\mathrm{Ca}^{2+}$ from the extracellular environment [65]. The cellular events underpinning the declining $\mathrm{Ca}^{2+}$ influx may attribute to the reduced/damaged mediated-channel, for instance, SOCE and TRPV3. Notably however, the unwounded $\mathrm{Ca}^{2+}$ oscillation could not guarantee intact fertilization response, the other downstream events may account for the senescence-mediated defects.

\section{Other potential channels mediate $\mathrm{Ca}^{2+}$ entry}

In addition to SOCE and TRP family member proteins, there are still other potential channels that mediate intracellular $\mathrm{Ca}^{2+}$ regulation. The $\alpha 1$ subunit of the T-type channel $\mathrm{Ca}_{\mathrm{v}} 3.2$, encoded by Cacna1h, also supports the entry of $\mathrm{Ca}^{2+}$ meiotic maturation and developmental activation. The function of T-type channels had been investigated in oocytes previously $[66,67] . \mathrm{Ca}^{2+} /$ calmodulin-dependent protein kinase II (CaMKII) was found to target T-type channels to activate Ach-induced $\mathrm{Ca}^{2+}$ current [68]. Cacna1h-/- females have reduced litter sizes, Cacna1h-/- or $\mathrm{Ca}_{\mathrm{v}} 3.2$-pharmacological inhibited eggs have reduced total and ER $\mathrm{Ca}^{2+}$ stores and turbulent $\mathrm{Ca}^{2+}$ oscillation patterns [22]. The exact mechanism of T-type channel regulation in oocytes and eggs requires further elucidation. Plasma membrane $\mathrm{Ca}^{2+}$-ATPase (PMCA) is a kind of $\mathrm{Ca}^{2+}$ pump-out channel that had been focused on. In presence of high concentrations of $\mathrm{Gd}^{3+}$, the initial $\left[\mathrm{Ca}^{2+}\right]_{\mathrm{i}}$ was broadened and the interval between spikes was widened, indicating the active participation of PMCA in $\left[\mathrm{Ca}^{2+}\right]_{\mathrm{i}}$ oscillations shaping [21]. ER plays a role as " $\mathrm{Ca}^{2+}$ reservoir" and is indispensable for $\mathrm{Ca}^{2+}$ oscillations. Replenishment and discharge of $\left[\mathrm{Ca}^{2+}\right]$ ER require sarco-endoplasmic reticulum $\mathrm{Ca}^{2+}$ ATPases (SERCA) and type 1 inositol 1,4,5-trisphosphate receptor (IP3R1) function during $\left[\mathrm{Ca}^{2+}\right]_{\mathrm{i}}$ oscillations. Addition of SERCA inhibitors (thapsigargin or cyclopiazonic acid (CPA)) could perturb $\mathrm{Ca}^{2+}$ oscillations by reducing basal $\left[\mathrm{Ca}^{2+}\right]_{\mathrm{ER}}$ levels and holding the recovery back $[21,23,24]$.

As an energy production center, the contribution of mitochondria to $\mathrm{Ca}^{2+}$ waves propagation cannot be ignored. Suppressing mitochondrial function destroyed $\left[\mathrm{Ca}^{2+}\right]_{i}$ vibration, blocked ER refilling of $\mathrm{Ca}^{2+}$ and thus enhanced $\left[\mathrm{Ca}^{2+}\right]_{\mathrm{i}}[21,69]$. ATP synthesis in mitochondria participated in $\left[\mathrm{Ca}^{2+}\right]_{\mathrm{ER}}$ refilling and normal oscillations maintaining, but there are other possibilities, including, just conceivably, it may uptake $\mathrm{Ca}^{2+}$ into the matrix [70].
Above all, the accomplishment of well-balanced $\mathrm{Ca}^{2+}$ oscillation during oocyte maturation and egg activation is achieved by the coordination of various types of channels. However, recent studies only rest on the enumeration of the phenomenon and the expression levels of different channels. All of this means it is imperative that more research should focus on the signal interactions and mechanisms involved in $\mathrm{Ca}^{2+}$ handling in the future.

\section{STRUCTURE AND FUNCTION OF PLC $\zeta$}

The identity of the "sperm factor" was initially confirmed to be protein, then the $\mathrm{Ca}^{2+}$ releasing function was found to depend on IP3R to produce IP3, and therewith, $\mathrm{Ca}^{2+}$-sensitive PLC became the most suspicion $[25,26,27,71,72]$. The true face of "sperm factor" was unveiled by Saunders group in 2002; they analyzed the testis-derived expressed sequence tags (ESTs) and sought out the novel testis-specific smallest PLC isoform, PLCל [28]. Complementary RNA (cRNA) and/ or protein microinjection and depletion assay verified the physiological role for $\mathrm{PLC} \zeta$ in $\mathrm{Ca}^{2+}$ oscillations, egg activation and embryo development during mammalian fertilization [28, 73, 74]. What's more, the direct evidence from the RNA interference transgenic mice further settled the status of PLCל [75]. And ICSI failure patients showed reduced/absent expression of PLC $\zeta 1$ in the sperm, such atypical PLC $\zeta$ protein expression may be explained by protein degradation/discard during spermatogenesis, instead of genomic abnormalities, and the expression regulation during spermatogenesis still worth to study in the future [76].

\section{The structural and functional basis of PLC $\zeta$}

As a smallest, constitutive mammal PLC isoform, PLC $\zeta$ employs a distinct mechanism to potently induce $\mathrm{Ca}^{2+}$ release in eggs in contrast with other PLC family members. Grasping the mechanism basic of protein domains could pave the way for intense research. PLC $\zeta$ possesses a tandem pair of EF hand-like domains in the $\mathrm{N}$-terminal, extended $\mathrm{X}$ and $\mathrm{Y}$ domains in the center region and a $\mathrm{C} 2$ domain in the $\mathrm{C}$-terminal, lacking of the pleckstrin homology $(\mathrm{PH})$ domain in other PLC isoforms [28]. To examine the role of each region of PLC $\zeta$, a series of domain-deletion/mutation constructs were created. EF hand domains and $\mathrm{C} 2$ domain had a major impact for XY catalytic activity $[77,78,79]$. The XY linker (the intervening region separates the catalytic $\mathrm{X}$ and $\mathrm{Y}$ domains) in PLC $\zeta$ stretches longer than PLC $\delta$ and owns the specific basic amino acid residues in the $\mathrm{Y}$ catalytic domain [28]. It was XY linker, instead of C2 domain, that possessed significant role in the targeting of PLC $\zeta$ to $\mathrm{PI}(4,5) \mathrm{P} 2$, which depending on the positive charge residues $[78,80]$. The relatively conservative positive 
charge residues may attract the positive charged PI $(4,5)$ P2. The sharp decrease of EC50 of PLC $\zeta$ after deletion of both $\mathrm{EF}$ hands domains indicated $\mathrm{Ca}^{2+}$ sensor role of EF hands, and further, the fact that replacement of PLC $\xi_{-}$ EF hands domain by PLC $\delta$-EF hands domain weakened $\mathrm{Ca}^{2+}$ sensitivity stressed the more effective capacity of PLC $\zeta-E F$ hands domain $[78,81]$. Apart from the XY linker, EF-hand domain containing positively-charged residues is also responsible for the PLC -targeting to the membrane PI(4,5)P2 [82]. Evidence supporting its role came from the halfway diminished function from the absence of XY linker, and the damaged PI(4,5)P2 binding from sequential reduction of the net positivecharged residues in EF-hand [80, 82]. In addition, EF-hand domains could be the last arbiter for the species-specific differences in PLC $\zeta$ (enzymatic properties and potency to elicit $\mathrm{Ca}^{2+}$ oscillations), proved by the exchanging human for mouse EF-hand assay [83]. Deletion/replacement of the $\mathrm{C} 2$ domain of $\mathrm{PLC} \zeta$ resulted in the inability to trigger $\mathrm{Ca}^{2+}$ oscillation in mouse eggs without PIP2 hydrolytic enzyme activity descend and $\mathrm{Ca}^{2+}$ sensitivity receding [77, 81]. Recently, a missense homozygous mutation had been found in PLC $\zeta-C 2$ domain of two patients, Phe 489 converted from Ile. Such mutation resulted in the missing of PLC $\zeta$ in sperm, turbulence of PLC $\zeta$ after injection in mouse oocytes, disordering $\mathrm{Ca}^{2+}$ variation and early embryonic arrest [84]. The mode of $\mathrm{C} 2$ domain action may be realized by its $\mathrm{PI}(3) \mathrm{P} / \mathrm{PI}(5) \mathrm{P}$ binding. On the one hand, such binding may help PLC $\zeta$ keep silent before working, on the other hand, this may help PLC $\zeta$ target the corresponding intracellular PIP2-containing vesicle. The post-translational modification is of great concern for PLC $\zeta$ to attain the functional ability. Proteolytic cleavage at the linker region between $\mathrm{X}$ - and Y-domains belongs to that, the two fragments kept performance unless immunodepletion/affinity-depletion [79]. Figure 3 summed up the possible functions of each domain of PLC $\zeta$.

The functional evaluation of PLC $\zeta$ could be identified as an indication of the fertilizing ability of sperm and clinical diagnostic information. It could be assessed from two perspectives: the reduced/absent PLC $\zeta$ protein abundance, the expressed mutated forms of PLC $\zeta$. The aberration of PLC $\zeta$ expression like reduction or missing was detrimental for egg activation and the follow-up steps in embryo development [76, 85, 86, 87]. The impact of residue-mutated $\mathrm{PLC} \zeta$ on $\mathrm{Ca}^{2+}$ movement is also illustrated in the following examples. Sperms in two infertile brothers all had genetic missence homozygous mutations in PLCל (Ile 489 Phe), which leading to the absence of PLC $\zeta$ in sperm and mis-distribution after injecting into eggs/oocytes, without distorting the sperm morphology [84]. The histidine residue replacement of proline at position 398 and histidine residue replacement of leucine at position 233 of PLC $\zeta$ were identified in a non-globozoospermic infertile male. Such mutations completely lack PIP2 (phosphatidylinositol 4,5-bisphosphate) hydrolysis ability in vitro and had lower protein instability when expressed in HEK293T cells [85, $88,89,90]$. Above all, figuring out the structure-function relationships underlying PLC $\zeta$ action is critical for understanding of the precise patterns of $\mathrm{Ca}^{2+}$ oscillations, oocyte activation and clinical applications.

Unlike other PLC isoforms in somatic cells, PLC $\zeta$ targeted the internal PI(4,5)P2 residing distinct vesicular structures inside the egg cortex. Substantial evidences existed to support this, just like minimal loss of oolemma PI(4,5)P2, no affect of depletion of oolemma $\mathrm{PI}(4,5) \mathrm{P} 2$ pool on $\mathrm{PLC} \zeta$-mediated $\mathrm{Ca}^{2+}$ oscillations, immunolocalization of related proteins and the inhibition effect of targeted vesicular PI(4,5)P2depletion [91]. Such distinctive feature is in exact accordance with physiological composition of PLC $\zeta$, as lack of a $\mathrm{PH}$ domain which specific binding to PM-PI $(4,5) \mathrm{P} 2$, and the soluble property that supports PLC $\zeta$ to diffuse throughout the cytoplasm. And even transforming the N-terminus of PLC $\zeta$ by annexation of PH domain from PLC $\delta 1$ did not alter its in vitro biochemical properties [81]. What's more, the distribution of $\mathrm{PI}(4,5) \mathrm{P} 2$ also changed with the vesicular distribution of the Golgi and other membranetrafficking systems. However, the exact domains mediate the binding with intracellular vesicles has remained a mystery.

PLC $\zeta$ complementary RNA injection could arouse fertilization-like $\mathrm{Ca}^{2+}$ oscillations in mice, cows, pigs and humans, and the optimal concentration of PLC $\zeta$ cRNA had been determined [74, 92, 93, 94]. These findings lay a solid foundation for future clinical reform and development to rescue human oocytes from failed activation. The active recombinant human PLC $\zeta$ protein was obtained recently. Kashir group firstly purified recombinant human PLCל protein and phenotypically rescued the failed activation in mouse oocytes, showing the great potential in clinical trials [88, 95]. Oocyte cytoplasmic movements was detected to change in near synchrony with the number and timing of $\mathrm{Ca}^{2+}$ transients after PLC $\zeta$ injection in aged human oocytes that failed to fertilize after ICSI [96]. The temporal analysis of movements could be measured by particle image velocimetry (PIV) analysis [96]. It promises to be a non-invasive approach for assessing the $\mathrm{Ca}^{2+}$ oscillations pattern in oocytes.

\section{IP3R acts as PLC $\zeta$ downstream pump-out channel on the ER membrane}

Diacylglycerol (DAG) and IP3 are two products of PLC $\zeta$ hydrolysis of PI(4,5)P2, IP3 then identifies and binds with IP3 receptors (IP3R), subsequently release the first $\mathrm{Ca}^{2+}$ wave from ER stores. IP3R1, tetrameric $\mathrm{Ca}^{2+}$ channels located on the membrane of ER, is responsible for the majority of $\left[\mathrm{Ca}^{2+}\right]_{\mathrm{i}}$ increases associated with 
fertilization [23, 24]. Such channel is composed of a channel pore formed by six transmembrane regions in C-terminal followed a small cytosolic tail, the coupling domain in intermediate region, and a ligand-binding domain in large cytosolic N-terminal region [97, 98]. IP3 is found to bind the coupling domain and could be converted into $\mathrm{Ca}^{2+}$ releasing from ER [99, 100]. Content and modification changes of IP3R1 are in accordance with the development of eggs. The level increased steadily with maturity, coinciding with maximal $\left[\mathrm{Ca}^{2+}\right]_{i}$ oscillatory ability at the MII stage, lost over half of the receptors in pronucleus stage, corresponding to the sperminitiated oscillations subsiding [101, 102, 103]. Persistent production and binding of IP3 facilitated its degradation and its degradation-regulation contributed to shaping the pattern of sperm-initiated $\left[\mathrm{Ca}^{2+}\right]_{i}$ oscillations [104]. In addition to IP3, $\mathrm{Ca}^{2+}$ can also act as a co-agonist [105]. On the other hand, phosphorylation of IP3R1 at the MPM-2 epitope by M-phase kinases (like p34cdc2 kinase, Cdk, MAPK and polo-like kinase-1 (Plk1)) enhances IP3R1mediated $\mathrm{Ca}^{2+}$ release in mouse and porcine eggs [106, 107, 108, 109]. The phosphorylation is initiated around the GVBD stage, corresponding with the activation of these kinases, which are responsible for the initiation and progression of oocyte maturation. Strikingly, the specific phosphorylated residue T930 within the coupling domain during rat oocyte mitosis could lower the binding affinity of IP3 to IP3R and thus resulted in lessened IP3-dependent $\mathrm{Ca}^{2+}$ release [110]. The above paradoxical effects caused by phosphorylation of diverse residues implicates that the crosstalk and combinatorial fashion define the ultimate biological function of IP3R. The molecular and signaling pathways were showed in Figure 3.

\section{The controversial PAWP}

PAWP, postacrosomal sheath WW domain-binding protein, locates in the post-acrosomal sheath region (PAS) of the perinuclear theca (PT) in elongating spermatids. It is composed of WW domain binding protein 2-similar homology in the N-terminal, PPXY consensus binding site for group-IWW domain-containing proteins, and numerous unique repeating motifs, YGXPPXG, in the C-terminal [29]. The performance of PAWP was tested by microinjection experiment and found that PAWP could promote MII oocyte meiotic resumption and pronuclear formation through its PY motif(s) [29].

While the effectiveness of PAWP to $\mathrm{Ca}^{2+}$ allocation is debatable, the battle of true identity of PAWP never ceased since its discovery. In 2015, two opposite research teams stated their points of view respectively in the same journal "Asian Journal of Andrology", referring to "Is PAWP the "real" sperm factor?" and "Re: Is PAWP the 'real' sperm factor?" [111, 112]. Facing doubts and disproval from Aarabi group and other groups, Nomikos group made their utmost efforts to fight for their point of view rigorously and precisely. Even so, scientists carried out more intense studies through sufficiently rigorous programmes. Later then, depending on the PAWP-knockout mouse model, the veil of PAWP's contribution to $\mathrm{Ca}^{2+}$ dynamics was further uncovered. Once again, the dispensable role of PAWP was supported by no indistinguishable changes in $\mathrm{Ca}^{2+}$ oscillations or in subsequent embryo development following gross depletion of PAWP [113]. The enigma that what PAWP does actually in other species on earth needs more exploration, maybe by means of new genome editing technologies, such as the CRISPR/Cas9 system.

\section{CONCLUSION AND PERSPECTIVES}

Most mammalian oocytes undergo cell-cycle arrest and resumption for two times during meiosis, and changes in $\mathrm{Ca}^{2+}$ homeostasis play a significant role in these two processes. The regulation of intracellular $\mathrm{Ca}^{2+}$ homeostasis involves $\mathrm{Ca}^{2+}$ in-out of extracellular and intracellular stores. Amidst all of this, $\mathrm{Ca}^{2+}$ influx not only maintains $\mathrm{Ca}^{2+}$ oscillations by replenishing $\mathrm{Ca}^{2+}$ stores during oocyte maturation, but also provides an important spatially restricted $\mathrm{Ca}^{2+}$ signal required for complete egg activation at fertilization [20, 37, 38]. SOCE and TRP family proteins are dominating channels mediating $\mathrm{Ca}^{2+}$ influx. In this review, we analyzed the channel composition and molecular effectors, especially the basic knowledge and spatial-temporal changes of SOCE and TRP family proteins (Figure 2). Still, there are big divergences over the research data from different groups such as the distribution of STIM1 in the cause of oocyte maturation. SOCE is not the only channel to achieve $\mathrm{Ca}^{2+}$ afflux in mouse oocytes, but in porcine oocytes, there is still no substitute for SOCE. Interestingly, the cooperation of SOCE and TRPM7 provide the researchers the new mechanism of action [36]. To make matters more puzzling and complicated, with the advent of oocyte-specific conditional knockout mice, many researchers are confused to weigh the influences of SOCE to oocyte development. As mentioned above, proteins-missing models showed no difference with the control group in the $\mathrm{Ca}^{2+}$ regulation [57]. The hidden truth needs people to expose in the future.

In most mammal species, $\mathrm{Ca}^{2+}$ oscillations actually begin at the time when the sperm and egg fuses. One or a few materials from the sperm provoke the first release of $\mathrm{Ca}^{2+}$ from intracellular $\mathrm{Ca}^{2+}$ stores and propagate the $\mathrm{Ca}^{2+}$ waves. PLC $\zeta$ is a candidate of sperm-specific factors. After releasing from sperm, PLC $\zeta$ binds and hydrolyzes internal $\mathrm{PI}(4,5) \mathrm{P} 2$ residing distinct vesicular structures into IP3 and DAG. As tetrameric $\mathrm{Ca}^{2+}$ channels located on the membrane of ER, IP3R1s take in IP3 and transform it into $\mathrm{Ca}^{2+}$ surge. Confronted with the intricate and multivariate factors in the action pathways, we went deep into and summarized the structural and modificatory regulation of $\mathrm{PLC} \zeta$-induced $\mathrm{Ca}^{2+}$ oscillation (Figure 3). In this process there still has many mysteries waiting for 
us to explore. For example, the specific PLC $\zeta$ antibodies used in different species and various laboratory protocols are still suspected along-standing puzzles. Multiple bands obtained from Western blotting could not definite the immunofluorescence or definite the position in sperms precisely, and in same species like human sperm, divergent results were received [76, 84, 85]. Therefore, the specificity and sensibility of the antibodies could not be neglected. Recently, Kashir group members exploited a novel, highly specific human PLC $\zeta$ antibody and a uniform protocol (antigen unmasking/retrieval protocols), which might raise the accuracy in clinical and basic science study of PLC $\zeta$ [114]. However, the feasibility and the universality still need more investigation, trials and tribulations. In the meantime, the true identity of PAWP is disputable since its discovery. Considering the limited overall evidence, more evidence of the links among PLC $\zeta$, PAWP and $\mathrm{Ca}^{2+}$ oscillations need to justified. More efforts should be redoubled to gain insight into the mechanism and molecular effectors that mediate the optimization of $\mathrm{Ca}^{2+}$ adjustment.

\section{Abbreviations}

$\mathrm{GV}$, germinal vesicle; MII, meiosis II; $\left[\mathrm{Ca}^{2+}\right]_{\mathrm{i}}$, cytosolic(intracellular) free calcium; $\left[\mathrm{Ca}^{2+}\right]_{\mathrm{ER}}$, endoplasmic reticulum $\mathrm{Ca}^{2+}$ store; SOCE, store-operated $\mathrm{Ca}(2+)$ entry; PM, plasma membrane; TRP, transient receptor potential;

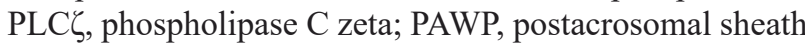
WW domain-binding protein; $\mathrm{LH}$, luteinizing hormone; GVBD, GV breakdown; ER, endoplasmic reticulum; $\mathrm{Ca}^{2+}$, calcium; $\left[\mathrm{Ca}^{2+}\right]_{\mathrm{e}}$, external $\mathrm{Ca}^{2+}$; PMCA, PM Ca ${ }^{2+}$-ATPase; SERCA, sarco-endoplasmic reticulum $\mathrm{Ca}^{2+}$ - ATPase; IP3R1, type 1 inositol 1,4,5-trisphosphate receptor; CPA, cyclopiazonic acid; PI(4,5)P2, phosphatidylinositol 4,5-biphosphate; IP3, inositol 1,4,5-trisphosphate; MPF, maturation-promoting factor; Cdk1, cyclin-dependent kinase $1 ; \mathrm{cdc} 2$, cell division cycle protein $2 ; \mathrm{APC} / \mathrm{C}$, anaphase promoting complex/cyclosome; CaMKII, type II $\mathrm{Ca}^{2+} /$ calmodulin-dependent protein kinase; ICSI, intracytoplasmic sperm injection; IVF, in vitro fertilization; STIM1, stromal interaction molecule 1

\section{Author contributions}

Y.-R. Xu and W.-X. Yang conceived of and authored the manuscript.

\section{ACKNOWLEDGMENTS}

The authors are grateful to all members of the Sperm Laboratory in Zhejiang University in their provision of valuable discussion.

\section{FUNDING}

This project was supported in part by the Natural Science Foundation of China (Nos. 31572603 and 41276151).

\section{CONFLICTS OF INTEREST}

The authors declare that there is no conflict of interest that could be perceived as prejudicing the impartiality of the review.

\section{REFERENCES}

1. Oh JS, Susor A, Conti M. Protein tyrosine kinase Wee1B is essential for metaphase II exit in mouse oocytes. Science. 2011; 332:462-465.

2. Kang H, Hwang SC, Park YS, Oh JS. Cdc25B phosphatase participates in maintaining metaphase II arrest in mouse oocytes. Mol Cells. 2013; 35:514-518.

3. Oh JS, Susor A, Schindler K, Schultz RM, Conti M. Cdc25A activity is required for the metaphase II arrest in mouse oocytes. J Cell Sci. 2013; 126:1081-1085.

4. Jones KT. Mammalian egg activation: from $\mathrm{Ca} 2+$ spiking to cell cycle progression. Reproduction. 2005; 130:813-823.

5. Nixon VL, Levasseur M, McDougall A, Jones KT. $\mathrm{Ca}(2+)$ oscillations promote APC/C-dependent cyclin B1 degradation during metaphase arrest and completion of meiosis in fertilizing mouse eggs. Curr Biol. 2002; 12:746750 .

6. Marangos P, Verschuren EW, Chen R, Jackson PK, Carroll J. Prophase I arrest and progression to metaphase I in mouse oocytes are controlled by Emil-dependent regulation of APC(Cdh1). J Cell Biol. 2007; 176:65-75.

7. Cho WK, Stern S, Biggers JD. Inhibitory effect of dibutyryl cAMP on mouse oocyte maturation in vitro. J Exp Zool. 1974; 187: 383-386.

8. Schultz RM, Montgomery RR, Belanoff JR. Regulation of mouse oocyte meiotic maturation: implication of a decrease in oocyte cAMP and protein dephosphorylation in commitment to resume meiosis. Dev Biol. 1983; 97:264273.

9. Dekel N, Aberdam E, Sherizly I. Spontaneous maturation in vitro of cumulus-enclosed rat oocytes is inhibited by forskolin. Biol Reprod. 1984; 31:244-250.

10. Mehlmann LM, Saeki Y, Tanaka S, Brennan TJ, Evsikov AV, Pendola FL, Knowles BB, Eppig JJ, Jaffe LA. The Gs-linked receptor GPR3 maintains meiotic arrest in mammalian oocytes. Science. 2004; 306:1947-1950.

11. Han SJ, Conti M. New pathways from PKA to the Cdc2/ cyclin B complex in oocytes: Wee1B as a potential PKA substrate. Cell Cycle. 2006; 5:227-231.

12. Dekel N, Lawrence TS, Gilula NB, Beers WH. Modulation of cell-to-cell communication in the cumulus-oocyte 
complex and the regulation of oocyte maturation by LH. Dev Biol. 1981; 86:356-362.

13. Norris RP, Ratzan WJ, Freudzon M, Mehlmann LM, Krall J, Movsesian MA, Wang H, Ke H, Nikolaev VO, Jaffe LA. Cyclic GMP from the surrounding somatic cells regulates cyclic AMP and meiosis in the mouse oocyte. Development. 2009; 136:1869-1878.

14. Adhikari D, Liu K. The regulation of maturation promoting factor during prophase I arrest and meiotic entry in mammalian oocytes. Mol Cell Endocrinol. 2014; 382:480487.

15. Stricker SA. Comparative biology of calcium signaling during fertilization and egg activation in animals. Dev Biol. 1999; 211:157-176.

16. Kline D, Kline JT. Repetitive calcium transients and the role of calcium in exocytosis and cell cycle activation in the mouse egg. Dev Biol. 1992; 149:80-89.

17. Jones KT, Carroll J, Merriman JA, Whittingham DG, Kono T. Repetitive sperm-induced $\mathrm{Ca} 2+$ transients in mouse oocytes are cell cycle dependent. Development. 1995; 121:3259-3266.

18. Marangos P, FitzHarris G, Carroll J. Ca2+ oscillations at fertilization in mammals are regulated by the formation of pronuclei. Development. 2003; 130:1461-1472.

19. Lee B, Palermo G, Machaca K. Downregulation of store-operated $\mathrm{Ca} 2+$ entry during mammalian meiosis is required for the egg-to-embryo transition. J Cell Sci. 2013; 126:1672-1681.

20. Miao YL, Stein P, Jefferson WN, Padilla-Banks E, Williams CJ. Calcium influx-mediated signaling is required for complete mouse egg activation. Proc Natl Acad Sci U S A. 2012; 109:4169-4174.

21. Wakai T, Zhang N, Vangheluwe P, Fissore RA. Regulation of endoplasmic reticulum $\mathrm{Ca}(2+)$ oscillations in mammalian eggs. J Cell Sci. 2013; 126:5714-5724.

22. Bernhardt ML, Zhang Y, Erxleben CF, Padilla-Banks E, McDonough CE, Miao YL, Armstrong DL, Williams CJ. CaV3.2 T-type channels mediate $\mathrm{Ca}^{2}+$ entry during oocyte maturation and following fertilization. J Cell Sci. 2015; 128:4442-4452.

23. Runft LL, Watras J, Jaffe LA. Calcium release at fertilization of Xenopus eggs requires type I IP(3) receptors, but not SH2 domain-mediated activation of PLC gamma or G(q)-mediated activation of PLCbeta. Dev Biol. 1999; 214:399-411.

24. Petersen $\mathrm{OH}$, Tepikin A, Park MK. The endoplasmic reticulum: one continuous or several separate $\mathrm{Ca}(2+)$ stores? Trends Neurosci. 2001; 24:271-276.

25. Berrie CP, Cuthbertson KS, Parrington J, Lai FA, Swann $\mathrm{K}$. A cytosolic sperm factor stimulates repetitive calcium increases and mimics fertilization in hamster eggs. Development. 1990; 110:1295-1302.

26. $\mathrm{Wu} \mathrm{H}, \mathrm{He} \mathrm{CL}$, Fissore RA. Injection of a porcine sperm factor triggers calcium oscillations in mouse oocytes and bovine eggs. Mol Reprod Dev. 1997; 46:176-189.

27. Wu H, Smyth J, Luzzi V, Fukami K, Takenawa T, Black SL, Allbritton NL, Fissore RA. Sperm factor induces intracellular free calcium oscillations by stimulating the phosphoinositide pathway. Biol Reprod. 2001; 64:13381349.

28. Saunders CM, Larman MG, Parrington J, Cox LJ, Royse J, Blayney LM, Swann K, Lai FA. PLC zeta: a spermspecific trigger of $\mathrm{Ca}(2+)$ oscillations in eggs and embryo development. Development. 2002; 129:3533-3544.

29. Wu AT, Sutovsky P, Manandhar G, Xu W, Katayama M, Day BN, Park KW, Yi YJ, Xi YW, Prather RS, Oko R. PAWP, a sperm-specific WW domain-binding protein, promotes meiotic resumption and pronuclear development during fertilization. J Biol Chem. 2007; 282:12164-12175.

30. Martín-Romero FJ, Ortíz-de-Galisteo JR, Lara-Laranjeira J, Domínguez-Arroyo JA, González-Carrera E, Alvarez IS. Store-operated calcium entry in human oocytes and sensitivity to oxidative stress. Biol Reprod. 2008; 78:307315.

31. Ma G, Wei M, He L, Liu C, Wu B, Zhang SL, Jing J, Liang X, Senes A, Tan P, Li S, Sun A, Bi Y, et al. Inside-out $\mathrm{Ca}(2+)$ signalling prompted by STIM1 conformational switch. Nat Commun. 2015; 6:7826.

32. Carvacho I, Lee HC, Fissore RA, Clapham DE. TRPV3 channels mediate strontium-induced mouse-egg activation. Cell Rep. 2013; 5:1375-1386.

33. Lee HC, Yoon SY, Lykke-Hartmann K, Fissore RA, Carvacho I. TRPV3 channels mediate $\mathrm{Ca}^{2+}$ influx induced by 2-APB in mouse eggs. Cell Calcium. 2016; 59:21-31.

34. Runnels LW, Yue L, Clapham DE. TRP-PLIK, a bifunctional protein with kinase and ion channel activities. Science. 2001; 291:1043-1047.

35. Carvacho I, Ardestani G, Lee HC, McGarvey K, Fissore RA, Lykke-Hartmann K. TRPM7-like channels are functionally expressed in oocytes and modulate postfertilization embryo development in mouse. Sci Rep. 2016; 6:34236.

36. Faouzi M, Kilch T, Horgen FD, Fleig A, Penner R. The TRPM7 channel kinase regulates store-operated calcium entry. J Physiol. 2017; 595:3165-3180.

37. Takahashi T, Kikuchi T, Kidokoro Y, Shirakawa H. Ca2+ influx-dependent refilling of intracellular $\mathrm{Ca} 2+$ stores determines the frequency of $\mathrm{Ca} 2+$ oscillations in fertilized mouse eggs. Biochem Biophys Res Commun. 2013; 430:60-65.

38. Cheon B, Lee HC, Wakai T, Fissore RA. Ca2+ influx and the store-operated $\mathrm{Ca} 2+$ entry pathway undergo regulation during mouse oocyte maturation. Mol Biol Cell. 2013; 24:1396-1410.

39. Parker NJ, Begley CG, Smith PJ, Fox RM. Molecular cloning of a novel human gene (D11S4896E) at chromosomal region 11p15.5. Genomics. 1996; 37:253256. 
40. Yeromin AV, Zhang SL, Jiang W, Yu Y, Safrina O, Cahalan MD. Molecular identification of the CRAC channel by altered ion selectivity in a mutant of Orai. Nature. 2006; 443:226-229.

41. Yamashita M, Yeung PS, Ing CE, McNally BA, Pomès R, Prakriya M. STIM1 activates CRAC channels through rotation of the pore helix to open a hydrophobic gate. Nat Commun. 2017; 8:14512.

42. Liou J, Kim ML, Heo WD, Jones JT, Myers JW, Ferrell JE Jr, Meyer T. STIM is a Ca2+ sensor essential for Ca2+store-depletion-triggered Ca2+ influx. Curr Biol. 2005; 15:1235-1241.

43. Muik M, Fahrner M, Derler I, Schindl R, Bergsmann J, Frischauf I, Groschner K, Romanin C. A Cytosolic Homomerization and a Modulatory Domain within STIM1 C Terminus Determine Coupling to ORAI1 Channels. J Biol Chem. 2009; 284:8421-8426.

44. Park CY, Hoover PJ, Mullins FM, Bachhawat P, Covington ED, Raunser S, Walz T, Garcia KC, Dolmetsch RE, Lewis RS. STIM1 clusters and activates CRAC channels via direct binding of a cytosolic domain to Orai1. Cell. 2009; 136:876-890.

45. Yuan JP, Zeng W, Dorwart MR, Choi YJ, Worley PF, Muallem S. SOAR and the polybasic STIM1 domains gate and regulate Orai channels. Nat Cell Biol. 2009; 11:337343.

46. Hou X, Pedi L, Diver MM, Long SB. Crystal structure of the calcium release-activated calcium channel Orai. Science. 2012; 338:1308-1313.

47. Yamashita M, Prakriya M. Divergence of $\mathrm{Ca}(2+)$ selectivity and equilibrium $\mathrm{Ca}(2+)$ blockade in a $\mathrm{Ca}(2+)$ releaseactivated $\mathrm{Ca}(2+)$ channel. J Gen Physiol. 2014; 143:325343.

48. Pozo-Guisado E, Campbell DG, Deak M, AlvarezBarrientos A, Morrice NA, Alvarez IS, Alessi DR, MartínRomero FJ. Phosphorylation of STIM1 at ERK1/2 target sites modulates store-operated calcium entry. J Cell Sci. 2010; 123:3084-3093.

49. Yazbeck P, Tauseef M, Kruse K, Amin MR, Sheikh R, Feske S, Komarova Y, Mehta D. STIM1 Phosphorylation at Y361 Recruits Orai1 to STIM1 Puncta and Induces Ca2+ Entry. Sci Rep. 2017; 7:42758.

50. Gómez-Fernández C, López-Guerrero AM, Pozo-Guisado E, Álvarez IS, Martín-Romero FJ. Calcium signaling in mouse oocyte maturation: the roles of STIM1, ORAI1 and SOCE. Mol Hum Reprod. 2012; 18:194-203.

51. Martín-Romero FJ, López-Guerrero AM, Alvarez IS, PozoGuisado E. Role of store-operated calcium entry during meiotic progression and fertilization of mammalian oocytes. Int Rev Cell Mol Biol. 2012; 295:291-328.

52. Gómez-Fernández C, Pozo-Guisado E, Gañán-Parra M, Perianes MJ, Alvarez IS, Martín-Romero FJ. Relocalization of STIM1 in mouse oocytes at fertilization: early involvement of store-operated calcium entry. Reproduction.
2009; 138:211-221.

53. Muik M, Fahrner M, Schindl R, Stathopulos P, Frischauf I, Derler I, Plenk P, Lackner B, Groschner K, Ikura M, Romanin C. STIM1 couples to ORAI1 via an intramolecular transition into an extended conformation. EMBO J. 2011; 30:1678-1689.

54. Wang C, Lee K, Gajdócsi E, Papp AB, Machaty Z. Orail mediates store-operated $\mathrm{Ca} 2+$ entry during fertilization in mammalian oocytes. Dev Biol. 2012; 365:414-423.

55. Wang C, Zhang L, Jaeger LA, Machaty Z. Store-Operated $\mathrm{Ca} 2+$ Entry Sustains the Fertilization $\mathrm{Ca} 2+$ Signal in Pig Eggs. Biol Reprod. 2015; 93:25.

56. Lee K, Wang C, Machaty Z. STIM1 is required for Ca2+ signaling during mammalian fertilization. Dev Biol. 2012; 367:154-162.

57. Bernhardt ML, Padilla-Banks E, Stein P, Zhang Y, Williams CJ. Store-operated Ca2+ entry is not required for fertilization-induced $\mathrm{Ca} 2+$ signaling in mouse eggs. Cell Calcium. 2017; 65:63-72.

58. Clapham DE, Julius D, Montell C, Schultz G. International Union of Pharmacology. XLIX. Nomenclature and structure-function relationships of transient receptor potential channels. Pharmacol Rev. 2005; 57:427-450.

59. Wu LJ, Sweet TB, Clapham DE. International Union of Basic and Clinical Pharmacology. LXXVI. Current progress in the mammalian TRP ion channel family. Pharmacol Rev. 2010; 62:381-404.

60. Peier AM, Reeve AJ, Andersson DA, Moqrich A, Earley TJ, Hergarden AC, Story GM, Colley S, Hogenesch JB, McIntyre P, Bevan S, Patapoutian A. A heat-sensitive TRP channel expressed in keratinocytes. Science. 2002; 296:2046-2049.

61. Jin J, Desai BN, Navarro B, Donovan A, Andrews NC, Clapham DE. Deletion of Trpm7 disrupts embryonic development and thymopoiesis without altering $\mathrm{Mg} 2+$ homeostasis. Science. 2008; 322:756-760.

62. Jin J, Wu LJ, Jun J, Cheng X, Xu H, Andrews NC, Clapham DE. The channel kinase, TRPM7, is required for early embryonic development. Proc Natl Acad Sci U S A. 2012; 109:E225-33.

63. Nadler MJ, Hermosura MC, Inabe K, Perraud AL, Zhu Q, Stokes AJ, Kurosaki T, Kinet JP, Penner R, Scharenberg AM, Fleig A. LTRPC7 is a Mg.ATP-regulated divalent cation channel required for cell viability. Nature. 2001; 411:590-595.

64. Runnels LW, Yue L, Clapham DE. The TRPM7 channel is inactivated by PIP(2) hydrolysis. Nat Cell Biol. 2002; 4:329-336.

65. Haverfield J, Nakagawa S, Love D, Tsichlaki E, Nomikos M, Lai FA, Swann K, FitzHarris G. Ca(2+) dynamics in oocytes from naturally-aged mice. Sci Rep. 2016; 6:19357.

66. Peres A. The calcium current of mouse egg measured in physiological calcium and temperature conditions. J Physiol. 1987; 391:573-588. 
67. Gallo A, Russo GL, Tosti E. T-type Ca2+ current activity during oocyte growth and maturation in the ascidian Styela plicata. PLoS One. 2013; 8:e54604.

68. Kang D, Hur CG, Park JY, Han J, Hong SG. Acetylcholine increases $\mathrm{Ca} 2+$ influx by activation of CaMKII in mouse oocytes. Biochem Biophys Res Commun. 2007; 360:476482.

69. Dumollard R, Marangos P, Fitzharris G, Swann K, Duchen $\mathrm{M}$, Carroll J. Sperm-triggered $[\mathrm{Ca} 2+]$ oscillations and $\mathrm{Ca} 2+$ homeostasis in the mouse egg have an absolute requirement for mitochondrial ATP production. Development. 2004; 131:3057-3067.

70. Rizzuto R, Pinton P, Carrington W, Fay FS, Fogarty KE, Lifshitz LM, Tuft RA, Pozzan T. Close contacts with the endoplasmic reticulum as determinants of mitochondrial Ca2+ responses. Science. 1998; 280:1763-1766.

71. Jones KT, Cruttwell C, Parrington J, Swann K. A mammalian sperm cytosolic phospholipase $\mathrm{C}$ activity generates inositol trisphosphate and causes $\mathrm{Ca} 2+$ release in sea urchin egg homogenates. FEBS Lett. 1998; 437:297300 .

72. Rice A, Parrington J, Jones KT, Swann K. Mammalian sperm contain a $\mathrm{Ca}(2+)$-sensitive phospholipase $\mathrm{C}$ activity that can generate $\operatorname{InsP}(3)$ from $\operatorname{PIP}(2)$ associated with intracellular organelles. Dev Biol. 2000; 228:125-135.

73. Kouchi Z, Fukami K, Shikano T, Oda S, Nakamura Y, Takenawa T, Miyazaki S. Recombinant phospholipase C zeta has high $\mathrm{Ca} 2+$ sensitivity and induces $\mathrm{Ca} 2+$ oscillations in mouse eggs. J Biol Chem. 2004; 279:10408-10412.

74. Rogers NT, Hobson E, Pickering S, Lai FA, Braude P, Swann K. Phospholipase C zeta causes Ca2+ oscillations and parthenogenetic activation of human oocytes. Reproduction. 2004; 128:697-702.

75. Knott JG, Kurokawa M, Fissore RA, Schultz RM, Williams CJ. Transgenic RNA interference reveals role for mouse sperm phospholipase Czeta in triggering $\mathrm{Ca} 2+$ oscillations during fertilization. Biol Reprod. 2005; 72:992-996.

76. Yoon SY, Jellerette T, Salicioni AM, Lee HC, Yoo MS, Coward K, Parrington J, Grow D, Cibelli JB, Visconti PE, Mager J, Fissore RA. Human sperm devoid of PLC, zeta 1 fail to induce $\mathrm{Ca}(2+)$ release and are unable to initiate the first step of embryo development. J Clin Invest. 2008; 118:3671-3681.

77. Kouchi Z, Shikano T, Nakamura Y, Shirakawa H, Fukami $\mathrm{K}$, Miyazaki S. The role of EF-hand domains and $\mathrm{C} 2$ domain in regulation of enzymatic activity of phospholipase C zeta. J Biol Chem. 2005; 280:21015-21021.

78. Nomikos M, Blayney LM, Larman MG, Campbell K, Rossbach A, Saunders CM, Swann K, Lai FA. Role of phospholipase C-zeta domains in $\mathrm{Ca} 2+$-dependent phosphatidylinositol 4,5-bisphosphate hydrolysis and cytoplasmic Ca2+ oscillations. J Biol Chem. 2005; 280:31011-31018.

79. Kurokawa M, Yoon SY, Alfandari D, Fukami K, Sato K,
Fissore RA. Proteolytic processing of phospholipase $\mathrm{C}$ zeta and $[\mathrm{Ca} 2+]$ i oscillations during mammalian fertilization. Dev Biol. 2007; 312:407-418.

80. Nomikos M, Elgmati K, Theodoridou M, Calver BL, Nounesis G, Swann K, Lai FA. Phospholipase C $\zeta$ binding to PtdIns(4,5)P2 requires the XY-linker region. J Cell Sci. 2011; 124:2582-2590.

81. Theodoridou M, Nomikos M, Parthimos D, GonzalezGarcia JR, Elgmati K, Calver BL, Sideratou Z, Nounesis G, Swann K, Lai FA. Chimeras of sperm PLC $\zeta$ reveal disparate protein domain functions in the generation of intracellular $\mathrm{Ca} 2+$ oscillations in mammalian eggs at fertilization. Mol Hum Reprod. 2013; 19:852-864.

82. Nomikos M, Sanders JR, Parthimos D, Buntwal L, Calver BL, Stamatiadis P, Smith A, Clue M, Sideratou Z, Swann K, Lai FA. Essential Role of the EF-hand Domain in Targeting Sperm Phospholipase C $\zeta$ to Membrane Phosphatidylinositol 4,5-Bisphosphate (PIP2). J Biol Chem. 2015; 290:2951929530.

83. Nomikos M, Theodoridou M, Elgmati K, Parthimos D, Calver BL, Buntwal L, Nounesis G, Swann K, Lai FA. Human PLC $\zeta$ exhibits superior fertilization potency over mouse $\mathrm{PLC} \zeta$ in triggering the $\mathrm{Ca}(2+)$ oscillations required for mammalian oocyte activation. Mol Hum Reprod. 2014; 20:489-498.

84. Escoffier J, Lee HC, Yassine S, Zouari R, Martinez G, Karaouzène T, Coutton C, Kherraf ZE, Halouani L, Triki C, Nef S, Thierry-Mieg N, Savinov SN, et al. Homozygous mutation of PLC $\zeta 1$ leads to defective human oocyte activation and infertility that is not rescued by the WWbinding protein PAWP. Hum Mol Genet. 2016; 25:878-891.

85. Heytens E, Parrington J, Coward K, Young C, Lambrecht S, Yoon SY, Fissore RA, Hamer R, Deane CM, Ruas M, Grasa P, Soleimani R, Cuvelier CA, et al. Reduced amounts and abnormal forms of phospholipase C zeta (PLC Ceta) in spermatozoa from infertile men. Hum Reprod. 2009; 24:2417-2428

86. Aghajanpour S, Ghaedi K, Salamian A, Deemeh MR, Tavalaee M, Moshtaghian J, Parrington J, Nasr-Esfahani MH. Quantitative expression of phospholipase C zeta, as an index to assess fertilization potential of a semen sample. Hum Reprod. 2011; 26:2950-2956.

87. Yelumalai S, Yeste M, Jones C, Amdani SN, Kashir J, Mounce G, Da Silva SJ, Barratt CL, McVeigh E, Coward $\mathrm{K}$. Total levels, localization patterns, and proportions of sperm exhibiting phospholipase $\mathrm{C}$ zeta are significantly correlated with fertilization rates after intracytoplasmic sperm injection. Fertil Steril. 2015; 104:561-568.

88. Kashir J, Jones C, Lee HC, Rietdorf K, Nikiforaki D, Durrans C, Ruas M, Tee ST, Heindryckx B, Galione A, De Sutter P, Fissore RA, Parrington J, et al. Loss of activity mutations in phospholipase $\mathrm{C}$ zeta (PLC $\zeta$ ) abolishes calcium oscillatory ability of human recombinant protein in mouse oocytes. Hum Reprod. 2011; 26:3372-3387.

89. Nomikos M, Elgmati K, Theodoridou M, Calver BL, 
Cumbes B, Nounesis G, Swann K, Lai FA. Male infertilitylinked point mutation disrupts the $\mathrm{Ca} 2+$ oscillation-inducing and PIP(2) hydrolysis activity of sperm PLC . Biochem J. 2011; 434:211-217.

90. Kashir J, Konstantinidis M, Jones C, Lemmon B, Lee HC, Hamer R, Heindryckx B, Deane CM, De Sutter P, Fissore RA, Parrington J, Wells D, Coward K. A maternally inherited autosomal point mutation in human phospholipase C zeta (PLCל) leads to male infertility. Hum Reprod. 2012; 27:222-231.

91. Yu Y, Nomikos M, Theodoridou M, Nounesis G, Lai FA, Swann K. PLC $\zeta$ causes $\mathrm{Ca}(2+)$ oscillations in mouse eggs by targeting intracellular and not plasma membrane PI(4,5) P(2). Mol Biol Cell. 2012; 23:371-380.

92. Yoneda A, Kashima M, Yoshida S, Terada K, Nakagawa S, Sakamoto A, Hayakawa K, Suzuki K, Ueda J, Watanabe T. Molecular cloning, testicular postnatal expression, and oocyte-activating potential of porcine phospholipase $\mathrm{C}$ zeta. Reproduction. 2006; 132:393-401.

93. Ross PJ, Beyhan Z, Iager AE, Yoon SY, Malcuit C, Schellander K, Fissore RA, Cibelli JB. Parthenogenetic activation of bovine oocytes using bovine and murine phospholipase C zeta. BMC Dev Biol. 2008; 8:16.

94. Yamaguchi T, Ito M, Kuroda K, Takeda S, Tanaka A. The establishment of appropriate methods for egg-activation by human PLC PLC $\zeta 1$ RNA injection into human oocyte. Cell Calcium. 2017; 65:22-30.

95. Nomikos M, Yu Y, Elgmati K, Theodoridou M, Campbell K, Vassilakopoulou V, Zikos C, Livaniou E, Amso N, Nounesis G, Swann K, Lai FA. Phospholipase C rescues failed oocyte activation in a prototype of male factor infertility. Fertil Steril. 2013; 99:76-85.

96. Swann K, Windsor S, Campbell K, Elgmati K, Nomikos M, Zernicka-Goetz M, Amso N, Lai FA, Thomas A, Graham C. Phospholipase $\mathrm{C}-\zeta$-induced $\mathrm{Ca} 2+$ oscillations cause coincident cytoplasmic movements in human oocytes that failed to fertilize after intracytoplasmic sperm injection. Fertil Steril. 2012; 97:742-747.

97. Patel S, Joseph SK, Thomas AP. Molecular properties of inositol 1,4,5-trisphosphate receptors. Cell Calcium. 1999; 25:247-264.

98. Bosanac I, Michikawa T, Mikoshiba K, Ikura M. Structural insights into the regulatory mechanism of IP3 receptor. Biochim Biophys Acta. 2004; 1742:89-102.

99. Mignery GA, Südhof TC. The ligand binding site and transduction mechanism in the inositol-1,4,5-triphosphate receptor. EMBO J. 1990; 9:3893-3898.

100. Rebecchi MJ, Pentyala SN. Anaesthetic actions on other targets: protein kinase $\mathrm{C}$ and guanine nucleotide-binding proteins. Br J Anaesth. 2002; 89:62-78.

101. Fujiwara T, Nakada K, Shirakawa H, Miyazaki S. Development of inositol trisphosphate-induced calcium release mechanism during maturation of hamster oocytes. Dev Biol. 1993; 156:69-79.
102. Parrington J, Brind S, De Smedt H, Gangeswaran R, Lai FA, Wojcikiewicz R, Carroll J. Expression of inositol 1,4,5-trisphosphate receptors in mouse oocytes and early embryos: the type I isoform is upregulated in oocytes and downregulated after fertilization. Dev Biol. 1998; 203:451461.

103. Jellerette T, Kurokawa M, Lee B, Malcuit C, Yoon SY, Smyth J, Vermassen E, De Smedt H, Parys JB, Fissore RA. Cell cycle-coupled $[\mathrm{Ca}(2+)](\mathrm{i})$ oscillations in mouse zygotes and function of the inositol 1,4,5-trisphosphate receptor-1. Dev Biol. 2004; 274:94-109.

104. Lee B, Yoon SY, Malcuit C, Parys JB, Fissore RA. Inositol 1,4,5-trisphosphate receptor 1 degradation in mouse eggs and impact on $[\mathrm{Ca} 2+]$ i oscillations. J Cell Physiol. 2010; 222:238-47.

105. Mak DO, McBride S, Foskett JK. Inositol 1,4,5-trisphosphate [correction of tris-phosphate] activation of inositol trisphosphate [correction of tris-phosphate] receptor $\mathrm{Ca} 2+$ channel by ligand tuning of $\mathrm{Ca} 2+$ inhibition. Proc Natl Acad Sci U S A. 1998; 95:15821-15825.

106. Lee B, Vermassen E, Yoon SY, Vanderheyden V, Ito J, Alfandari D, De Smedt H, Parys JB, Fissore RA. Phosphorylation of IP3R1 and the regulation of $[\mathrm{Ca} 2+]$ i responses at fertilization: a role for the MAP kinase pathway. Development. 2006; 133:4355-4365.

107. Ito J, Yoon SY, Lee B, Vanderheyden V, Vermassen E, Wojcikiewicz R, Alfandari D, De Smedt H, Parys JB, Fissore RA. Inositol 1,4,5-trisphosphate receptor 1, a widespread $\mathrm{Ca} 2+$ channel, is a novel substrate of polo-like kinase 1 in eggs. Dev Biol. 2008; 320:402-413.

108. Ito J, Yoshida T, Kasai Y, Wakai T, Parys JB, Fissore RA, Kashiwazaki N. Phosphorylation of inositol 1,4,5-triphosphate receptor 1 during in vitro maturation of porcine oocytes. Anim Sci J. 2010; 81:34-41.

109. Zhang N, Yoon SY, Parys JB, Fissore RA. Effect of M-phase kinase phosphorylations on type 1 inositol 1,4,5-trisphosphate receptor-mediated $\mathrm{Ca} 2+$ responses in mouse eggs. Cell Calcium. 2015; 58:476-488.

110. Haun S, Sun L, Hubrack S, Yule D, Machaca K. Phosphorylation of the rat $\operatorname{Ins}(1,4,5) \mathrm{P} 3$ receptor at $\mathrm{T} 930$ within the coupling domain decreases its affinity to Ins(1,4,5)P3. Channels (Austin). 2012; 6:379-384.

111. Aarabi M, Sutovsky P, Oko R. Re: Is PAWP the 'real' sperm factor? Asian J Androl. 2015; 17:446-449.

112. Nomikos M, Swann K, Lai FA. Is PAWP the "real" sperm factor? Asian J Androl. 2015; 17:444-446.

113. Satouh Y, Nozawa K, Ikawa M. Sperm postacrosomal WW domain-binding protein is not required for mouse egg activation. Biol Reprod. 2015; 93:94.

114. Kashir J, Buntwal L, Nomikos M, Calver BL, Stamatiadis P, Ashley P, Vassilakopoulou V, Sanders D, Knaggs P, Livaniou E, Bunkheila A, Swann K, Lai FA. Antigen unmasking enhances visualization efficacy of the oocyte activation factor, phospholipase $\mathrm{C}$ zeta, in mammalian 
sperm. Mol Hum Reprod. 2017; 23:54-67.

115. Maruyama T, Kanaji T, Nakade S, Kanno T, Mikoshiba K. 2APB, 2-aminoethoxydiphenyl borate, a membranepenetrable modulator of Ins $(1,4,5) \mathrm{P} 3$-induced $\mathrm{Ca} 2+$ release. J Biochem. 1997; 122:498-505.

116. Chubanov V, Mederos y Schnitzler M, Meißner M, Schäfer $\mathrm{S}$, Abstiens K, Hofmann T, Gudermann T. Natural and synthetic modulators of SK (K(ca)2) potassium channels inhibit magnesium-dependent activity of the kinase-coupled cation channel TRPM7. Br J Pharmacol. 2012; 166:13571376.

117. Hofmann T, Schäfer S, Linseisen M, Sytik L, Gudermann T, Chubanov V. Activation of TRPM7 channels by small molecules under physiological conditions. Pflugers Arch. 2014; 466:2177-2189.

118. Zhang D, Pan L, Yang LH, He XK, Huang XY, Sun FZ. Strontium promotes calcium oscillations in mouse meiotic oocytes and early embryos through InsP3 receptors, and requires activation of phospholipase and the synergistic action of InsP3. Hum Reprod. 2005; 20:3053-3061.

119. Morgan AJ, Jacob R. Ionomycin enhances $\mathrm{Ca} 2+$ influx by stimulating store-regulated cation entry and not by a direct action at the plasma membrane. Biochem J. 1994; 300:665672 .
120. Xu H, Delling M, Jun JC, Clapham DE. Oregano, thyme and clove-derived flavors and skin sensitizers activate specific TRP channels. Nat Neurosci. 2006; 9:628-635.

121. Ebner T, Montag M, Oocyte Activation Study Group, Montag M, Van der Ven K, Van der Ven H, Ebner T, Shebl O, Oppelt P, Hirchenhain J, Krüssel J, Maxrath B, Gnoth $\mathrm{C}$, et al. Live birth after artificial oocyte activation using a ready-to-use ionophore: a prospective multicentre study. Reprod Biomed Online. 2015; 30:359-365.

122. Cheek TR, McGuinness OM, Vincent C, Moreton RB, Berridge MJ, Johnson MH. Fertilisation and thimerosal stimulate similar calcium spiking patterns in mouse oocytes but by separate mechanisms. Development. 1993; 119:179189.

123. Palmer AE, Jin C, Reed JC, Tsien RY. Bcl-2-mediated alterations in endoplasmic reticulum $\mathrm{Ca} 2+$ analyzed with an improved genetically encoded fluorescent sensor. Proc Natl Acad Sci U S A. 2004; 101:17404-17409.

124. Bird GS, Putney JW Jr. Capacitative calcium entry supports calcium oscillations in human embryonic kidney cells. J Physiol. 2005; 562:697-706.

125. Martin RL, Lee JH, Cribbs LL, Perez-Reyes E, Hanck DA. Mibefradil block of cloned T-type calcium channels. J Pharmacol Exp Ther. 2000; 295:302-308. 